Session 3430

\title{
Active Collaborative Learning
}

\section{in a Live Distance Education Class}

\author{
Donald Flugrad, Barbara Licklider, Anthony Hron,
}

Kandace Martin, Justin Benna

Iowa State University

I. Introduction

Colleges and universities across the nation are finding themselves in the midst of several learning revolutions. Recognizing that the traditional classroom no longer meets the needs of the student, "the old telling-method" of delivering education is being replaced with a new learner and/or learning-centered platform of delivery. ${ }^{1}$ Research states that the unilateral dispensing of knowledge is an ineffective method for enhancing student learning.

Supporting this finding about learning requires educators to confront how they think and to redesign what they do as a result. The shift from the lecture-based, passive-learning model to a learning-centered system of learning does not just happen. It requires a purposeful faculty development project that challenges instructors to commit to positive change. Such change in the classroom creates active involvement, student interaction, and intellectual engagement. Additionally, implementing new pedagogy will empower students to become actively involved in the class. But the active, collaborative model becomes more challenging to implement when the students are miles apart and from diverse backgrounds and experiences.

How does the instructor who has made this philosophical shift enhance communication, build community, and facilitate learning through the use of collaborative strategies in a distance education class? A mechanical engineering instructor, with the help of two Project LEA/RN ${ }^{\mathrm{TM}}$ facilitators, set out to answer this question in one distance education class. This paper describes our efforts.

\section{Faculty Development}

As the learning revolution slowly infiltrates college campuses, one of the keys to making a paradigm shift is through faculty involvement in an interactive development program that allows instructors to come together as learners to learn about learning. ${ }^{1}$ Another goal of faculty development is to enhance student learning by assisting faculty to investigate how and why students learn, to deepen student learning through effective teaching strategies and to incorporate effective cooperative learning methodology in the classroom. Through the commitment of the instructor, the classroom is transformed from a "telling" classroom to an active, collaborative environment. On the campus of Iowa State University, Project LEA/RN"T , a faculty development effort to promote change, has directed the shift from the traditional teacher-centered classroom to a learning-centered one in which students actively transform information into knowledge. Personnel who have joined the Project have acquired the skills, expertise, and desire to apply current knowledge about learning. ${ }^{2}$ 


\section{Incorporating Learning-centeredness into a Distance Education Classroom}

A mechanical engineering professor who was assigned a distance education course, had gained knowledge and expertise in student learning as a participant in one of the Project LEA/RN ${ }^{\mathrm{TM}}$ groups. He has incorporated a number of collaborative activities into classes he meets face-to-face, and is thoroughly convinced that this approach is a significant improvement over the strict lecture-mode of teaching.

During the Spring 1999 term, he taught his first distance education class using live video and audio connections to three remote sites and, a group of on-campus. This advanced mechanism design class relied heavily on graphic figures and vector mathematics for understanding. It proved to be very difficult to engage the students, particularly those at the remote sites, in any sort of interactive communication during class time. This situation was aggravated by the fact that only one remote site was visible on the monitors at a time, and the instructor did not directly control which site was visible. The system was voice-activated, so if someone at one of the remote sites spoke up, that site then captured control and appeared to all other locations. During the Fall 1999 term, when he was assigned to teach a course in advanced dynamics of machinery over the same distance education network, he sought special assistance from facilitators of Project LEA/RNTM. Their purpose was to help Dr. Flugrad develop more effective techniques to communicate with all students at the various sites and to improve communication among the students. Improving communication from instructor to student, student to instructor and student to student was identified as a critical first step in developing an enhanced learning environment for all participants.

\section{Improving Communication and Building Community}

In a distance education class, electronic communication systems serve as the delivery method that replaces or supplements the face-to-face classroom. For many distance education courses, the web site serves as the information hub for posting all types of course information such as the syllabus, assignments, Power Point notes, and participant questions and comments. In addition, electronic mail, fax, teleconferencing, overnight express and regular mail service facilitate delivery of course materials, getting/giving feedback, answering questions, and sending take-home tests.

But technology is not enough. Building community depends upon communication between and among learners. Community is a dynamic group that shares common practices, depends on each other, and makes decisions jointly. Group members identify themselves with something larger than the sum of their individual relationships, and make a commitment to the well being of the group, individually and collectively. ${ }^{3}$ A classroom is built through a learning process that links interactions between and among faculty and students. ${ }^{4}$ We believe that building a learning community is extremely important in the creation of a successful distance learning classroom. How is this accomplished? More specifically, how did we set out to build community in this distance education classroom?

\section{Facilitating the Process}

With the technology in place and building a learning community as our goal, purposefully planned interactive strategies became our link. One of the main tasks of the instructor was to design a class structure and determine learning strategies that allow students to actively engage in the learning process and to communally facilitate the creation of their own meaning from the content of the course.

Researched-based strategies were used to begin the community-building process. Initially, the students introduced themselves at each site and gave background and job-related information during class. Throughout the course, the students were called upon by name, thus increasing the opportunity to identify names and faces. Expanding on the need to know participants in and between each site, the students were given an inter-site, job-related problem. By posting the solution on the web for the entire class to read, this project not only developed community but also linked the course content to a reality-based problem.

Classroom strategies kept the students actively engaged in constructing their own meanings - the backbone of learning. A collaborative strategy taught to Project LEA/RNTM groups enables students to dialogue with the person next to them. During class, the instructor would assign a problem to solve. Students were asked to turn to a person 
near them and to then explore a solution to the problem. This deceptively simple collaborative strategy allows students to generate deeper levels of meaning.

To further expand the learning opportunities, to build community, and to gain valuable real world skills, assignmentspecific base groups were established. A base group is a small number of students (approximately 4) that support learning by offering "assistance in completing asignments," holding "each other accountable," and ensuring that "all members are making good academic progress. ${ }^{5}$ These base groups included students from each of the sites. Groupings were posted on the web site. The first assignment required the students to perform an inverse dynamic analysis and a dynamic analysis of a slider crank mechanism. This allowed the students an opportunity to build a collaborative view of the material being discussed that extended beyond the ideas each held at the start. The students were asked to present their findings to the class in a five-minute presentation much like they are required to do in industry.

The second project promoted another collaborative approach to learning. New base groups were formed among students at the individual sites. Groups were again given a problem to solve that required them to develop a collaborative solution to a kinematic analysis of spatial slide crank mechanism, thus further building a community of learners.

Throughout the term, interactive strategies were implemented, base groups were formulated, and collaborative assignments were given. Were we successful in generating a communication network between and among the students? Were effective communication pathways developed in order to facilitate the building of community? Did the learning strategies enhance student learning? An analysis of the communication structure and strategies that build community among the four sites began with classroom observations by the two faculty development facilitators. A series of meetings were scheduled with the instructor and facilitators to examine the implementation of interactive strategies and discuss additional ways of fostering communication between the four sites. Mid-term and final evaluations of the course were posted on the web site for responses from the participants. In addition, focus groups were scheduled to gather information and comments from the participants at each site. The collected data indicated that the participants were very eager to give their feedback and offered a plethora of insights, which are incorporated in the next section.

\section{Participant Input}

Several issues emerged from a qualitative review of student comments, classroom observations, and course artifacts (i.e. course evaluations and student grades). These issues can be grouped under the following headings: 1) the effectiveness of electronic and face-to-face communication, and 2) the success of collaborative learning approaches. Our analysis of this student input will be provided in Section VII. What We Learned.

\section{Effectiveness of communication}

Because our assumption was that effective communication enhances the development of a learning community, we attempted to facilitate communication in a number of ways. The following insights regarding the effectiveness of this effort were derived from the data. These insights include information regarding: the live video linkage between the classrooms, the class web site, and electronic mail.

1. The technology that links the four sites consists of an interface between two electronic systems. The class originates on the campus of ISU and is distributed via the Iowa Communication Network (ICN). The three remote sites located at various John Deere corporate offices are interlinked with their own teleconferencing system. These teleconferencing system interfaces with the ICN to provide live audio/video between the four sites. Because these systems are not $100 \%$ compatible, technical difficulties periodically interrupted the connection between the sites. However, all sites received videotape after each session. At each site students commented on the need for "good video connections."

2. The internet further provided immediate access to the course web site. One student indicated that the web site was a "good place when they need to put something out there and you need to be able to get it - like a take home test that you're supposed to download and do and fax back." The web site proved to be a valuable resource for posting class documents assignments, tests, examples and solutions to problems. A discussion board was used to post an assignment that allowed students to generate more applicable examples. One student commented that "you got to see some more practical examples." The web site allowed not only the instructor but also the students a "meeting place" to post and answer questions and comments. 
3. Another communication device that students used extensively was electronic mail (email). One student commented that if "we want to communicate something we always have the list set up for e-mail." Another student added, "Yea, for transferring files e-mail is more efficient. These tools assist in shrinking the miles between sites and building the basis for a learning community to develop."

The results indicate that the students want tools to support communication. The findings reveal a further belief by the students that the existing tools could be more effective in facilitating communication to enhance their learning. Students became disillusioned and frustrated with the ICN/Deere system breakdowns that interrupted the class presentations and interactions. Further, students noted that simplifying the web site would more easily facilitate posting additional articles, examples and work related scenarios.

Many students also revealed a desire to communicate more directly with the instructor or other technical resource person such as a teaching assistant or an industry teaching partner. Most students indicated that interaction with the instructor was important. All of the on-campus students said that they had sought the help of the instructor or the teaching assistant at least once during the semester. Students at one off-campus site indicated a strong desire to have the instructor or teaching assistant visit their site to answer questions and build rapport. This visit was seen as an opportunity to create greater familiarity between the instructional staff and students thus making electronic communication more comfortable. However, this sentiment was not held by all students. At a different remote site, students felt that such visits were unnecessary, either to answer questions or to improve electronic communication. "We talk to each other about lecture and see if we understand it..." Another student commented that "if I don't understand, I ask another person in the class to explain it."

Success of collaborative learning approaches

A desired outcome in this classroom was the development of an interactive learning environment. As previously noted, strategies to promote interaction and collaboration were used throughout the course. Students responded with diverse comments concerning the various strategies. The strategy of working with a partner to explore a solution to a question or problem was viewed favorably by students at two of the sites. At a third remote site one student interjected, "I'm not sure the interaction is worth while." Another person at the site felt that the strategy produced "5 minutes of dead time." That remote site maintained that usually one person came up with the answer and shared it with others in the group. The desired outcome was not fully achieved because the students used a short cut. Students at the other two sites agreed that the strategy helps to break up a lecture but also allows for time to confer with a partner to solve a problem. Several students at one of the sites indicated the desire for more time to collaborate during class.

For the first project, the students were assigned to multi-site groups. The students did not know each other prior to this assignment. Students from all sites noted that they had to trust other members and "assume the rest of the group was doing the work." Most all of the groups divided the project into parts. Their basic mode of communication was email. The student feedback centered on two themes: 1) the members were "not sure what the other individuals in the group were doing until the end." 2) The work was "divided up" which hurt the participants because they did not get the "full experience." Several indicated that they would have liked to work through the entire process not just a specific segment. The students were given class time to present their findings.

The presentations, which were given to the class by the groups of students, allowed all groups time to explain the process used to extract their findings. One student emailed the following insight, "I think the class presentations today were an effective way to foster class interaction. I had to work with my teammates to supply me information. That is how we work in business...More presentations would help us polish the presentation skills needed in industry. The business unit managers eat people alive if the presenter is not prepared. Many experienced engineers have had to learn effective presentation skills."

The second project assigned students to same-site groups. It was observed that that the students quickly formed their groups and began reviewing the time schedule and methods needed to finish the project. The students said that it was easier and faster to meet with students face-to-face than using a communication tool such as email, fax, or a telephone.

Another successful assignment required the students to post an article on the web site and explain how it related to the class content. The students commented on the benefits of reading the articles. They indicated that this would 
have been more beneficial had they been allowed to discuss different aspects of the articles. Although they could post questions for the class on the web, they felt that an interactive discussion during class would have been "more practical, applicable and beneficial."

A final note on the success of collaborative strategies involves students working in isolation at remote sites. One off-campus site had only one student. He spoke about the detrimental effects of not having a learning partner at the site. "It would have been easier if another student was here."

In summary, the research results suggest that students in this distance education class utilized all of the communication tools provided. They found value in the interactive and collaborative strategies used, but to varying degrees. The students valued the group projects but suggested more structure. They spoke strongly about connecting the material learned during class to practical work-related situations. Finally, the students built learning communities at each site, but perhaps the greatest evidence of this was at the two multi-student remote sites. Students used one another as learning partners, teaching assistants and mentors.

\section{What We Learned}

The results of this research provided us with valuable insights. First, we learned not to make assumptions about the existing community at remote sites. Second, we learned that the level of preexisting community within a site influenced the development of community between sites. Third, we learned that in order for collaborative approaches to work effectively the benefits need to be clearly articulated to the students and the approaches need to be structured to take advantage of the technology.

First, we made assumptions that initially hampered our efforts to build community. As discovered later, participants at one John Deere site did not know the other colleagues in their classroom. Many of these participants didn't work in the same building. At another remote site, students developed a sense of community prior to this class because of their close working relationships. Although we had the students introduce themselves during the first class, ideally we should have allowed for all the participants to engage in a more extensive dialogue about their work, classes, educational background, or other pertinent information throughout the semester. We think that students' familiarity with each other is crucial for building a sense of community in the classroom. We learned that this community building process needs to be repeated frequently to ensure familiarity between the students.

Second, we never anticipated that a preexisting sense of community within a remote site might hamper the development of community between remote sites. We found that one remote site resisted our efforts to create community between sites because they already relied heavily upon classmates at their own site to work collaboratively. Comments from this site revealed that the strength of community within their group overshadowed the need for collaboration with students from other sites. This contrasted with the experience of students at another remote site that did not have a strong sense of community prior to attending this class. These students found that collaboration with classmates from other sites was extremely beneficial to their learning experience. The revelation of these attitudes has caused us to re-evaluate our original assumption that the development of community between remote sites will always enhance student learning. Other models for creating community in distance classrooms might also enhance student learning. It might be possible to develop each remote site as a self-sufficient learning community that does not require collaborations between sites. This model could work if each site was large enough to function as a community. Another variation on developing community in remote classrooms would be to treat each site according to its individual needs. Some sites might be treated as fully functioning communities by themselves and other sites might be required to work together in order to create a sense of community. In situations where the remote sites have only one student or a group of students who do not have a sense of community, our experience indicates that the goal of developing community between sites would provide the greatest benefit to student learning.

Third, we learned that the students need to know the rationale for using collaborative learning strategies. This rationale is based on research which indicates that the sharing of knowledge and resources leads to greater student learning. This benefit can only be fully realized if technology is used to its full potential. For example, establishing on-line office hours, chat rooms, and message boards utilizes the full potential of electronic communication to 
advance learning. In addition, expanding the usage of the ICN/Deere telecommunication network beyond class time for base group conferences could allow for more effective collaboration. We believe that as instructors and students become more savvy with electronic communication they will be able to gain greater benefits from active, collaborative learning strategies.

\section{Final Remarks}

One of the main goals of education is to prepare students for the new millennium in a world that is transitioning from an information age to a knowledge-based era. Students need to be able to construct knowledge using different resources, skills, roles and relationships. ${ }^{5}$ The old paradigm that holds sacred the teacher-based model of providing information will not develop the type of person needed to keep pace with a knowledge-based environment. Effective faculty development programs help instructors create the kind of change within classrooms that will empower learners to construct knowledge using communication and collaboration. Distance education offers the potential to build better interactive classrooms that foster learning communities, but clearly more exploration of this medium is needed. Learning by distance is the future, and the learning that happens through this medium must be dramatically enhanced. We offer initial strategies to increase that learning while we are seeking additional knowledge in this area. Is there any reason to NOT use what we already know can make distance education more effective?

\section{Bibliography}

1. Fulton, C., Licklider, B.L. \& Schnelker, D.L., Revisioning faculty development: Improving teaching and learning. Journal of Staff Programs and Organizational Developments. New Forums Press (1997).

2. Ibid.

3. Schaffer,C.\&Anundsen,K. Creating community anywhere. New York: Jeremy P. Tarcher/Perigee Books (1993).

4. $\quad$ Palloff R.M. \& Pratt, K. Building learning communities in cyberspace. San Francisco: Jossey-Bass Publishers (1999).

5. Johnson, D. W., Johnson, R. T., Smith, K. A., Active learning: Cooperation in the college classroom. Minnesota: Interaction Book Company (1998).

6. Palloff R.M. \& Pratt, K. Building learning communities in cyberspace. San Francisco: Jossey-Bass Publishers (1999).

\section{Acknowledgements}

Project LEA/RNTM (Learning Enhancement Action/Resource Network) is a faculty improvement model developed to improve student learning by enhancing professors' knowledge and skills related to learning and teaching. This work is supported by the Center for Teaching Excellence, College of Engineering, College of Education, and numerous contracts and grants.

\section{Biography}

\section{DONALD FLUGRAD}

Donald Flugrad is an Associate Professor and Associate Chair of the Mechanical Engineering Department of Iowa State University in Ames, Iowa. He worked for five years on office products for IBM and has worked four summers at the John Deere Des Moines Works on projects related to agricultural products. He has been actively engaged in teaching and research related to mechanism and machine design at ISU for the past 22 years. 


\section{BARBARA LICKLIDER}

Barbara Licklider has successfully directed the efforts of Project LEA/RNTM a faculty development project on the ISU campus since 1994. Dr. Licklider is an Associate Professor in Educational Leadership and Policy Studies within the College of Education and Director of Education Student Services at Iowa State University.

\section{ANTHONY HRON}

Anthony Hron is a Temporary Assistant Professor in the Department of Landscape Architecture at Iowa State University. In August of 1999 he joined the Project LEA/RN staff to help facilitate active learning in a variety of disciplines.

\section{KANDACE MARTIN}

Kandace Martin is Assistant Director of Project LEA/RNTM. Previously she was a classroom teacher and most recently an administrator in secondary education

\section{JUSTIN BENNA}

Justin Benna is Special Projects Coordinator for Project LEA/RNTM. After working for Project LEA/RNTM asa graduate research assistant for three years, Justin now works full time facilitating faculty LEA/RN ${ }^{\text {TM }}$ groups and cooperative learning workshops. 